\title{
Digestive System Findings Domain
}

National Cancer Institute

\section{Source}

National Cancer Institute. Digestive System Findings Domain. NCI Thesaurus. Code C102640.

A subject domain utilized for the submission of information encompassing and representing data, vocabulary or records related to digestive system findings. 